\title{
How do green areas influence the temperature of cities? Web map to help local decision making about cities and the climate emergency
}

\author{
Carla Garcia-Lozano ${ }^{a}$, Anna Péliováa ${ }^{a}$ and Josep Sitjar ${ }^{\mathrm{a}}$ \\ carla.garcia@udg.edu , an.peliova@gmail.com, josep.sitjar@udg.edu
}

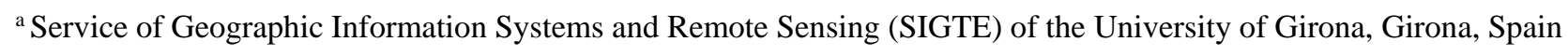

\begin{abstract}
The positive effect of urban greenery on the city's microclimate is well known, as is its ability to reduce the ambient temperature in urban areas. Our results show how the areas with the lowest surface temperature clearly coincide with the vegetated areas in the city of Barcelona. This phenomenon demonstrates the importance of increasing the urban greenery in large compact cities, such as the city of Barcelona, in order to regulate the local temperature and mitigate the effects of global warming on a large scale. The web map presented here can be used as a tool for decision makers to identify the warmest areas in the city of Barcelona and to increase greenery in an efficient manner.
\end{abstract}

Keywords: urban heat island, land surface temperature, normalized difference vegetation index, greenery area, climate change, Landsat 8, Barcelona.

\section{Introduction}

The ambient temperature of urban areas is usually higher than the temperature of the surrounding landscape. This phenomenon is known as the Urban Heat Island (UHI) (Manley, 1958; Oke, 1973). Vehicle emissions, industrial and commercial activities, and the fact that the roofs of large building structures, roads and other solid materials absorb solar radiation and subsequently reradiate it into the surrounding area, all contribute to the temperature rise in the city (Nuruzzaman, 2015). However, urban areas with vegetation have a significantly lower surface temperature than built-up areas (Akbari et al., 1998; Masson, 2006).

The objective of this research is to visually demonstrate how the land surface temperature is influenced by vegetation in the municipality of Barcelona. The visualization presented here enables urban planners to identify the most vulnerable areas of the city with regard to a global issue: the climate emergency. The data collected for the analysis, as well as the data gathered to develop the web map, is all open data available from Open Data BCN and the United States Geological Survey (USGS) websites.

\section{Methology}

In order to visualize the relationship between lower temperatures and urban greenery in Barcelona, two types of data were used: vegetation cover and land surface temperature.

The vegetation cover of the city of Barcelona is available on the Open Data BCN website, while the land surface temperature (LST) after atmospheric correction was retrieved from the thermal infrared imagery acquired by the multispectral scanner of the

Landsat 8 satellite on July 6, 2019, at 10:30 UTC, when the atmospheric temperature in Barcelona was $26^{\circ} \mathrm{C}$.

In order to retrieve the LST, a method based on previous research was used (Dobrovolný, 2012; Onačillová, 2018). The first step was to calculate the top of the atmosphere reflectance (LTOA).

$$
L_{T O A}=M_{L} Q_{c a l}+A_{L}
$$

To eliminate the atmospheric impact we used an equation with atmospheric correction parameters (band average atmospheric transmission $\tau$, effective bandpass upwelling radiance $L u$, effective bandpass downwelling radiance $L d$ ) calculated specifically for the imagery (https://atmcorr.gsfc.nasa.gov/). The equation for eliminating atmospheric impact includes calculating the emissivity $(\varepsilon)$ of real surface which was estimated from the Normalized Difference Vegetation Index (NDVI). This method was proposed by Liu and Zhang (2011). 
Table 1 Algorithm for calculating emissivity according to NDVI

\begin{tabular}{|c|c|}
\hline NDVI & Emissvity (ع) \\
\hline NDVI $<-0.185$ & 0.995 \\
\hline$-0.185 \leq \mathrm{NDVI}<0.157$ & 0.985 \\
\hline $0.157 \leq \mathrm{NDVI} \leq 0.727$ & $1.009+0.047 * \ln (\mathrm{NDVI})$ \\
\hline NDVI $>0.727$ & 0.990 \\
\hline
\end{tabular}

Using the algorithm in Tab.1, each pixel was assigned a value according the class to which it belongs. The next step consisted of calculating the radiance of black body surface $(L T)$.

The surface temperature in Kelvins was then calculated, using a formula where $K_{1}$ and $K_{2}$ are specific thermal conversion constants for bands.

In the final step, the LST in Kelvins was converted into the LST in Celsius degrees.

The estimated LST might not be correct in all parts, a fact that is caused by the original resolution of thermal imagery, which was $100 \mathrm{~m}$ resampled to $30 \mathrm{~m}$.

With the goal of quantifying how the land surface temperature is correlated with vegetation cover, the NDVI was used. The NDVI was calculated using the Near Infrared (NIR) and Red channels of multispectral imagery.

The NDVI calculation is based on using the spectral characteristic of vegetation, specifically the chlorophyll which absorbs the red light of solar radiance and reflects near infrared (Pettorelli, 2013). This index is a simple but effective method typically used for monitoring the health of vegetation whose values range from -1 to +1 . Negative values usually signify water bodies, whereas values close to +1 stand for denser vegetation cover.

\section{Results and discussion}

The estimated land surface temperature on July 6, 2019 at 10:30 UTC in Barcelona reached a maximum temperature of $56.1^{\circ} \mathrm{C}$ and a minimum temperature of $27.3^{\circ} \mathrm{C}$. These temperatures might be considered too high; however, this value refers to the land surface temperature rather than the air temperature, which was $26^{\circ} \mathrm{C}$ at that moment.

It is well known that, among many other positive environmental impacts, urban greenery has a positive effect on the city's microclimate and can help to reduce the temperature (Masson, 2006; Nuruzzaman, 2015; Oliveira et al., 2011; Susca et al., 2011; Zoulia et al., 2009). The visualization presented here (https://mapscloud.udg.edu/sigtedataviz2019/) shows how the areas with the lowest land surface temperature clearly coincide with the vegetated areas. This dynamic map visually shows the effects of heat island and can be a tool for the administration to identify the most critical areas where it would be necessary to take action.

The coolest areas (expressed in blue and green in Figure 1) of the municipality of Barcelona are located in forested and elevated environments around the city, namely the Collserola Mountain Range, where the LST was less than $30^{\circ} \mathrm{C}$ on the day sampled. The same can be said of urban green spaces, especially large parks or gardens, such as Ciutadella Park, Diagonal Mar Park and Montjuïc Mountain Gardens, whose surface temperatures range between 30 and $35^{\circ} \mathrm{C}$.

Meanwhile, the areas with the highest temperature (corresponding to the dark red tones in Figure 1) are concentrated in the industrial sectors of BesòsMontsolís and Zona Franca.

The NDVI was correlated with the LST by means of a regression line where Pearson's coefficient is reported with the objective of quantifying how much the land surface temperature is related to the vegetation cover. 

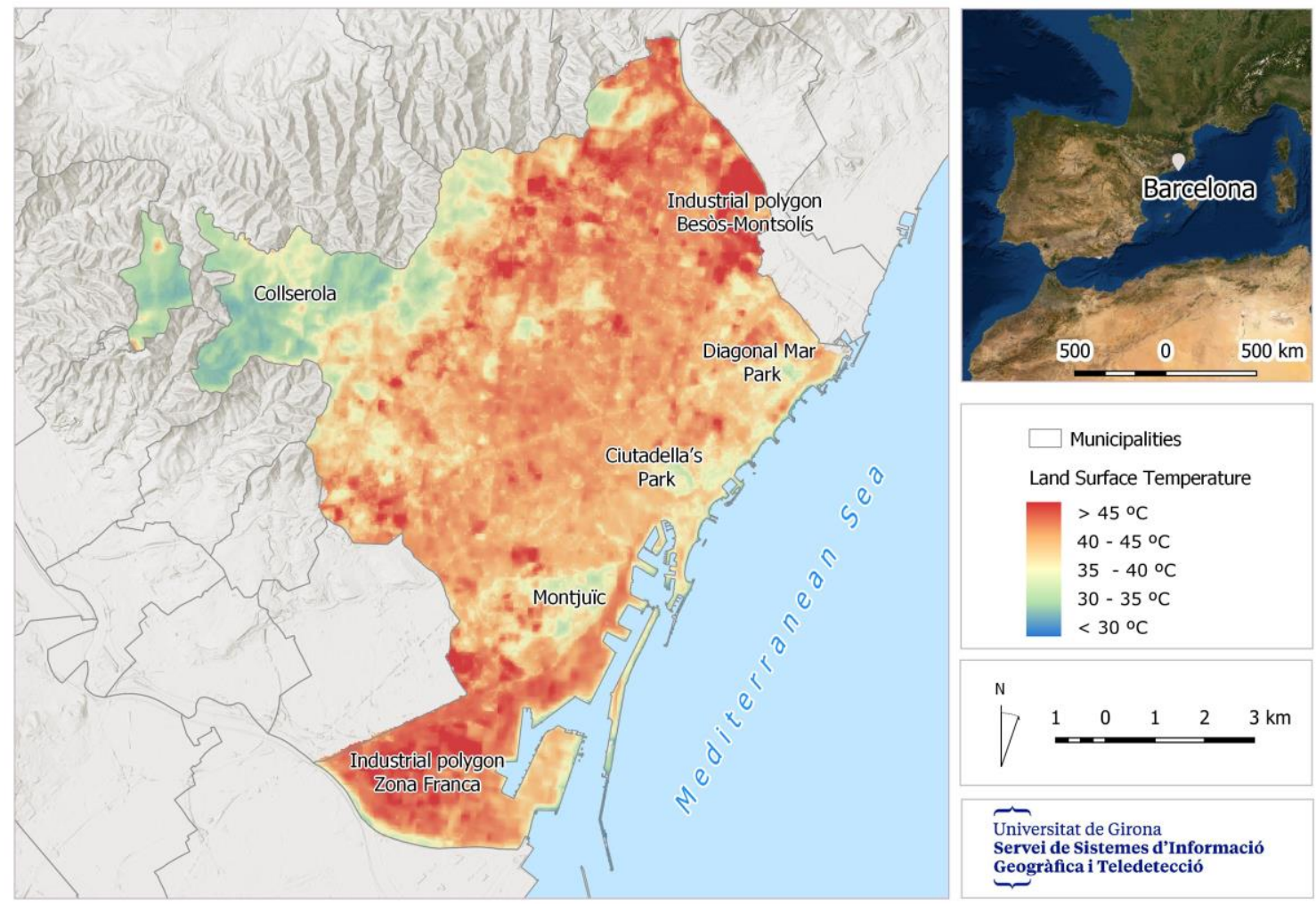

Figure 1. Land surface temperature in the city of Barcelona
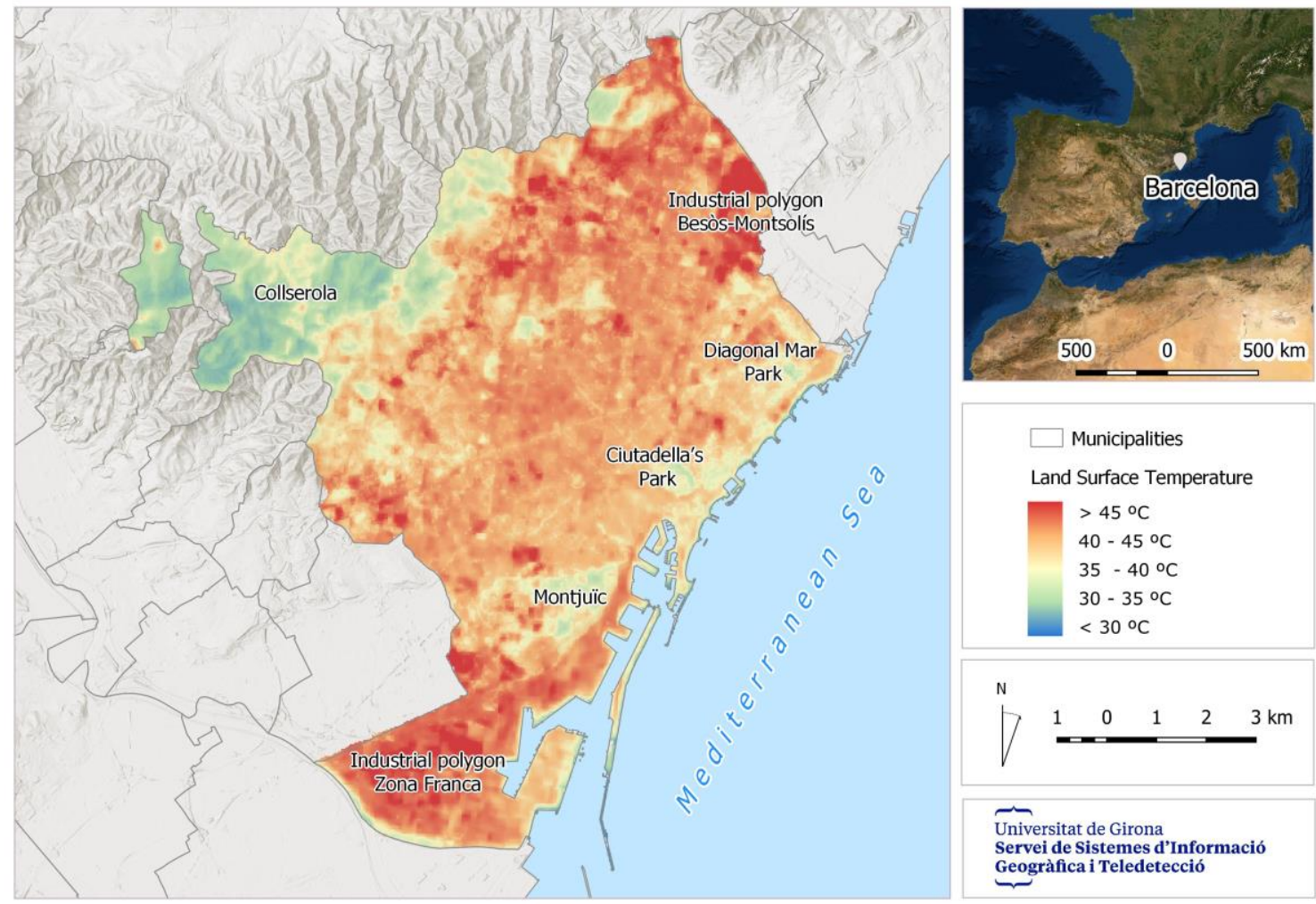

Figure 2. Land surface temperature and vegetation cover in Barcelona. The areas with the lowest surface temperature clearly coincide with the vegetated areas. 
The drop in temperature is also evident in the small green areas of the city (Figure 2). Apart from the Ciutadella Park, which is one of the coolest places in the urban area of the city, the main tree-lined avenues also contribute to decreasing land surface temperatures. The main green avenues were around $35-40^{\circ} \mathrm{C}$ on July 6, 2019. Rambla de Catalunya or Rambla del Raval, for instance, located in the Ciutat Vella district, are the coolest places in Barcelona's old quarter. Meanwhile, Gran Via de les Corts Catalanes, despite its dense traffic, has low temperatures due to being a tree-lined avenue. The LST is also lower on the tree-lined Avinguda Diagonal Avenue, which cuts across the entire city of Barcelona.

On the other hand, industrial areas have the highest surface temperatures across the city (Figure 2). The thermal radiation of the roofs of industrial units and the production activity that goes inside these units make industrial areas the warmest zones in the city (Akbari et al., 1998; Nuruzzaman, 2015).

Vegetation has an impact even on a small scale: city blocks with interior gardens also mitigate the warming that occurs in big cities. The Eixample district of Barcelona is characterized by long straight streets, a strict grid pattern crossed by wide avenues and square blocks with chamfered corners. The Eixample district was designed by the architect Ildefons Cerdà. His original idea was to create green areas in the district.

However, his original plan was modified by the city's urban planners, who significantly increased the built-up areas in detriment to the interior gardens. Today, only a few blocks conserve the original idea of increasing greenery in the city.

With the goal of highlighting the drop in temperature in the city's small gardens, we chose the example of the Paula Montal and Emma interior gardens, located on Carrer Viladomat, Barcelona (Figure 3). The LST in the surrounding blocks is between 40 and $45^{\circ} \mathrm{C}$, whereas the temperature decreases to $35-40^{\circ} \mathrm{C}$ in the blocks with interior gardens. The presence of vegetated areas within built-up areas therefore contributes to a decrease in surface temperature in the order of between 5 and $10^{\circ} \mathrm{C}$.

Both the cartographic representations and the web map presented here (https://mapscloud.udg.edu/sigtedataviz2019/) clearly illustrate the existence of a relationship between surface temperature and the presence of vegetation.
Nevertheless, this paper quantifies to what extent these variables are related to the case of Barcelona. The pixel values of the NDVI and LST maps were correlated by means of a regression line (Figure 4) with the goal of quantifying how the land surface temperature is related to the vegetation cover. The inversely proportional trend between both variables $(R=-0.69)$ confirms that the coolest areas in the city are located in the urban areas covered by vegetation.

Each point in Figure 4 represents the values of NDVI and LST pixels. The NDVI values range from -1 to +1 where negative values correspond to water bodies, whereas values close to +1 stand for denser vegetation cover. In the case of the municipality of Barcelona, NDVI values range from -0.1 to 0.57 where values between 0.2 and 0.35 correspond to tree-lined avenues and small gardens with trees, while those higher than

0.35 coincide with the city's main gardens and parks, as well as the forested areas in the Collserola Mountain Range. Values below 0.2 correspond to the built-up areas. Finally, no negative values were located as water bodies of significant size are not present in the city of Barcelona.

Other research has also pointed out a high correlation between temperature and vegetation in big cities (Masson, 2006; Nuruzzaman, 2015; Oke, 1973). In this respect, some previous research highlighted the importance of planting trees in streets and increasing the vegetation on roofs and in the interior area of city blocks in order to mitigate the temperature rise in big cities (Oliveira et al., 2011; Susca et al., 2011; Wong \& Yu, 2004; Zoulia et al., 2009). In addition, green roofs would also help to decrease the pollution levels in the city and to keep the inside of houses cooler and better soundproofed.

According to the Living Roofs and Green Covers Plan of Barcelona City Council, 67\% of the city's buildings have flat and accessible roofs suitable for vegetation (Ajuntament de Barcelona, 2015). Apart from decreasing warming in the city, the use and rehabilitation of roofs, roof terraces and courtyards provide many other benefits. From an environmental point of view, they increase greenery and biodiversity, facilitating a reduction of energy demand and promoting energy production systems with natural resources. All of these measures contribute to helping buildings and cities adapt to climate change, thus increasing the resilience of cities. 


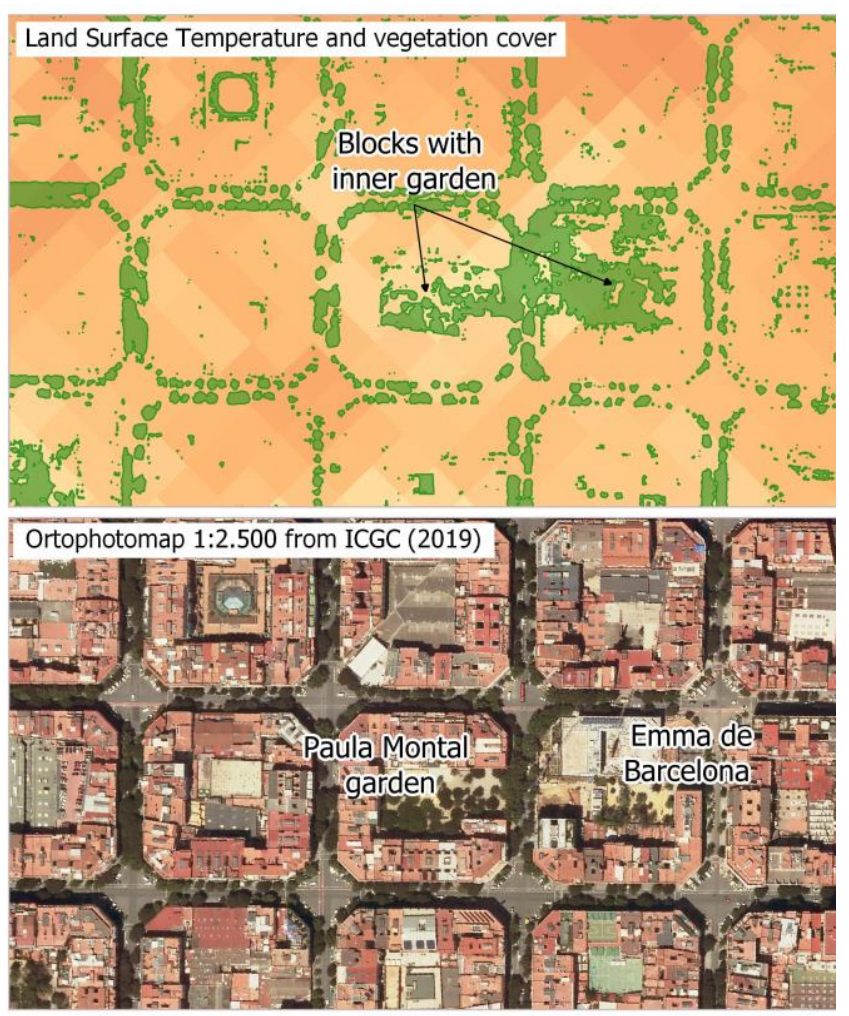

Figure 3. Land surface temperature and vegetation cover in blocks with interior gardens.

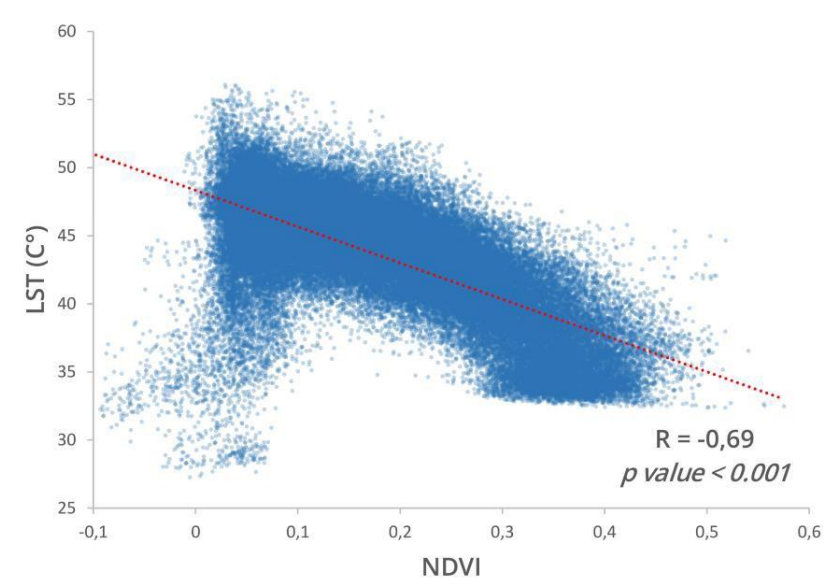

Figure 4. The relationship between lower land surface temperatures (LST) and vegetation cover (NDVI) is very significant, with an inversely proportional trend between the variables $(R=$ 0.69), which means that the parts with lower temperatures coincide with the vegetated areas of the city.

\section{Conclusions}

The surface temperature of the city of Barcelona is clearly influenced by the number of green areas and tree-lined avenues in the city. The areas which concentrate higher temperatures are situated in the built-up areas where the presence of trees is scarce. In contrast, green areas such as parks and gardens are the coolest spaces in the city.

Despite vehicle emissions, the decrease in temperature is also evident on the main tree- lined avenues in the city, which have an average temperature of $5-10^{\circ} \mathrm{C}$ less than the surrounding areas. The cooling effect of smallscale vegetation in urban spaces is also perceptible: the interior gardens of city blocks also lower the temperature significantly.

Conversely, industrial areas are the warmest spaces in the city. The thermal radiation of the roofs of industrial units and the production activity that goes on inside these units are the main cause of the temperature increase.

Planting more trees in streets and increasing the presence of vegetation on roofs and in city block interiors would contribute to mitigating temperature rises in big cities. The web map presented here can be used as a tool for decision makers in order to identify the warmest areas in the city of Barcelona and to increase greenery in an efficient manner.

interior gardens of city blocks also lower the temperature significantly.

Conversely, industrial areas are the warmest spaces in the city. The thermal radiation of the roofs of industrial units and the production activity that goes on inside these units are the main cause of the temperature increase.

Planting more trees in streets and increasing the presence of vegetation on roofs and in city block interiors would contribute to mitigating temperature rises in big cities. The web map presented here can be used as a tool for decision makers in order to identify the warmest areas in the city of Barcelona and to increase greenery in an efficient manner.

\section{References}

Ajuntament de Barcelona: Guide to living terrace roofs and green roofs. Online publication available at: 
https://bcnroc.ajuntament.barcelona.cat/jspui/bitstream /11703/98795/5/Guia\%20de\%20terrats\%20vius\%20i \%20cobertes\%20verdes\%20ang1\%c3\%a8s.pdf 2015

Akbari, H., Gartland, L., \& Konopacki, S.: Measured energy savings of light colored roofs: Results from three California demonstration sites: Lawrence Berkeley National Lab., Environmental Energy Technologies Div., Berkeley, CA (United States). 1998

Dobrovolný, P.: The surface urban heat island in the city of Brno (Czech Republic) derived from land surface temperatures and selected reasons for its spatial variability. Theoretical and Applied Climatology, 112(1-2), pp. 89-98. 2012

Liu, L., Zhang, Y.: Urban Heat Island Analysis Using the Landsat TM Data and ASTER Data: A Case Study in Hong Kong. Remote Sensing, 3(7). 2011

Masson, V.: Urban surface modeling and the mesoscale impact of cities. Theoretical and Applied Climatology, 84(1-3), 35-45. 2006

Manley, G.: On the frequency of snowfall in metropolitan England. Quarterly Journal of the Royal Meteorological Society, 84, pp. 70-72. 1958

Nuruzzaman, M.: Urban heat island: causes, effects and mitigation measures-a review. International Journal of Environmental Monitoring and Analysis, 3(2), 67-73. 2015

Oke, T.R.: City size and the urban heat island. Atmospheric Environment Pergamon Press, 7: 769779. 1973

Oliveira, S., Andrade, T., Vaz, T.: The cooling effect of green spaces as a contribution to the mitigation of urban heat: A case study in Lisbon. Building and Environment, 46(11): 2186-2194. 2011

Onačillová, K., Gallay.M.: Spatio-temporal analysis of surface urban heat island based on Landsat ETM+ and OLI/TIRS imagery in the city of Košice, Slovakia. Carpathian Journal of Earth and Enviromental Sciences, 13(2), pp. 395-408. 2018

Susca, T., Gaffin, S.R., Dell'Osso, G.R.: Positive effects of vegetation: Urban heat island and green roofs. Environmental Pollution, 159(8-9): 2119-2126. 2011

Wong, N.H., Yu, C.: Study of green areas and urban heat island in a tropical city. Habitat International, 29(3): 547-558. 2004

Zoulia, I., Santamouris, M. \& Dimoudi, A.: Monitoring the effect of urban green areas on the heat island in Athens. Environ Monit Assess 156:275-292. 2009
Pettorelli, N.: The normalized difference vegetation index. Oxford University Press. 2013 